\title{
Automatic Processes Underlying Implicit Spelling Activation in the Auditory Rhyme Decision Task
}

\author{
Eleni Lipourli \\ University of the Aegean, Rhodes, Greece
}

\begin{abstract}
The present paper examines the processes underlying the activation of orthography in children and adults. Two experiments are reported, one conducted on adults and one conducted on children of 9 and 11 years of age, that examined whether the orthographic effects in the auditory rhyme decision task are automatic, or whether they arise from some form of strategically mediated process. The specific question asked is whether the orthographic effects may be modified by an experimental manipulation of the proportion of trials on which spelling and rhyme are incongruent. If they are not then this would suggest that the activation of spelling reflects an automatic process in this task. The results from the experiment with adults showed very clearly that the orthographic facilitation effect for responses to rhymes and the orthographic inhibition effect for responses to non-rhymes were not reliably different for subjects biased towards the use of spelling to assist rhyme decisions and those biased away from the use of spelling. The 11-year-old children tested also showed that they cannot be biased, as they activate the spellings of the words they hear, even though they are not asked to do so, totally automatically. However, the 9-year-old children did show a bias (or 'set') effect; only those who were biased towards the use of spelling similarity showed a reliable orthographic facilitation effect.
\end{abstract}

\section{Introduction}

It has been found [1] that there are clear effects of orthographic knowledge in performance in the auditory rhyme decision task. This task requires an explicit judgement upon a major aspect of a spoken word's phonology, namely the appreciation of whether or not it rhymes with a previously presented word. In order to perform this task, the subjects must hold a phonological representation of the first word and then compare it with the phonological representation of the second word to determine whether or not the terminal vowel plus consonant segments (i.e., the phonological rimes) of the two words are the same or different. It is most likely that this requires the subjects to segment the two phonologically held representations of the words into their onsets and rimes. Although it is possible that the rhyme decision task could be performed by some matching process of the words' whole phonological representations, primary weighting would need to be given to the end halves of the words in order to produce accurate performance, and so this strategy appears to be a less probable one.

The effects of spelling similarity in the auditory rhyme decision task occur even though the subjects are not asked either to activate or to consult orthographic information; indeed, the instructions stress that subjects should attend to the sounds of the two words. Ostensibly, therefore, the rhyme decision task is a purely phonological one; it should be able to be performed using phonological information alone. Indeed, it can be performed without orthographic knowledge, as some children can decide if two words rhyme before they can read and spell, and adults are able to decide if two spoken nonwords rhyme or not [2] [3] [4] [5]. It is evident that there are effects of orthography on people's reaction times to make auditory rhyme decisions: there is a facilitation effect demonstrated on positive responses to rhymes and an inhibition effect on negative responses to non-rhymes [1]. These effects suggest that people activate the spellings of the words they hear in the auditory rhyme decision task and that this orthographic knowledge influences their performance. Findings suggest that orthographic activation also underlies auditory word recognition [6].

The aim of the two experiments to be reported in this paper is to consider whether the orthographic effects in the auditory rhyme decision task are automatic or whether they arise from some form of strategically mediated process. It is possible that the orthographic effects observed in rhyme decisions reflect strategic activation and use of spelling by participants. It might be argued that, when presented with tasks requiring explicit, formal decisions on aspects of word phonology (and particularly those either requiring or encouraging some form of segmentation of that phonology, as in rhyme decisions), literate subjects will activate all the 
information that is available to them [7]. This argument might also be extended to how people might make rhyme decisions on spoken nonwords and words they do not know how to spell. Nonwords have no stored spelling representations, but it may be possible to assemble orthographic codes that might assist performance [8]. Although it is true that sound-to-spelling correspondences are inconsistent in English, it might be expected that the similarity of the assembled spelling of two words or nonwords should be able to give a generally useful clue to whether they rhyme or not. However this strategy is not going to be an efficient one because, as it will be described in the method section, the constitution of the stimulus materials of the experiments reported below is such that for half of all trials spelling and sound are not congruent: half of all the rhyming pairs have different spelling patterns of their rimes (e.g., "head-red"), and half of all pairs of words with similar spelling patterns do not rhyme (e.g., "mint-pint"). This is because there are four major conditions, each with equal numbers of trials: rhyme pairs with similar spellings, rhymes with dissimilar spellings, non-rhymes with similar spellings, and non-rhymes with dissimilar spellings.

The specific question asked by the two experiments to be reported in this paper is whether the orthographic effects may be modified by an experimental manipulation of the proportion of trials on which spelling and rhyme are incongruent. Will varying the proportion of similarly-spelled pairs have an effect upon rhyme and non-rhyme decisions? If they do not, then this would suggest that the activation of spelling reflects an automatic process in this task. Both Experiments 1 and 2 contained two phases. In the first phase, subjects performed the auditory rhyme decision task under one of two conditions. Half of the subjects (group A) were presented with rhyming pairs all of which had similar spelling patterns (e.g., "wild-child") and nonrhyming words all of which were spelled differently (e.g., "joke-room"). For this group it was reasoned that if orthographic activation is under some degree of strategic control, then these subjects should be encouraged to activate and use the spelling of the words to assist their rhyme decisions. The subjects in group A should be biased towards the use of spelling, as in all instances spelling similarity and rhyme will be congruent. However, the other half of the subjects (group B) were presented with rhyming pairs all of which had dissimilar spelling patterns (e.g., "floor-war") and non-rhyming words all of which were spelled with similar patterns (e.g., "paidsaid"). It was reasoned that this group would be biased away from the use of spelling, as in all instances spelling similarity and rhyme will be in conflict. (Although it is logically possible that the perfect negative correlation between spelling similarity and rhyme might assist subjects in group
B, who could respond "yes, the words rhyme" because they have different spelling patterns, this seems to be rather unlikely to be used in practice.) It must be stressed, however, that the instructions never explicitly 'directed' subjects either towards or away from the use of spelling similarity to assist their rhyme decisions. Rather, it was reasoned that the composition of the stimulus materials might affect any strategic reliance upon such spelling similarity to assist efficient performance in the rhyme decision task.

In the second phase of each experiment, subjects were presented with the usual four sets of stimulus word pairs: (i) rhyming word pairs with similar spelling patterns; (ii) rhyming pairs with dissimilar spelling patterns; (iii) non-rhyming pairs with similar spelling patterns; and (iv) non-rhyming pairs with dissimilar spelling patterns. Furthermore, responses to the first and second halves of the trials in the second phase of each experiment will be compared in order to explore the duration of any possible effect of the strategic activation of spelling that might be developed in the first phase. If the biases towards or away from spelling which were hoped to have been evoked by the first phase of the experiment were only transient, then it might be expected that they would only be found for the early trials of the second phase. However, if the orthographic effects are truly automatic, then they should be expected to be found for the early (and indeed for the very first) trials of the second phase of the experiment.

Experiment 1 was performed with adults and Experiment 2 was performed with children of two different ages. The major purpose of comparing subjects of different ages (9-year-olds, 11-year-olds and adults), was to investigate the possibility that any automatic activation of spelling develops with increasing literate competence.

\section{Experiment 1: Set effects in adults}

\subsection{Method}

2.1.1. Participants. Thirty-four (eight male and twenty six female) students of the University of Wales, Cardiff, participated in the experiment for approximately ten minutes each. They were either paid or received course credit for their participation.

2.1.2. Design. Four independent variables were manipulated in the experiment. The first was the between subjects factor of group, where group A was biased towards using spelling and group B was biased away from using spelling in phase I of the experiment. The next three variables, which were manipulated within-subjects, concerned the stimuli presented in phase II of the experiment. These variables were: rhyme (rhyme vs. non-rhyme); spelling (similar vs. dissimilar); and block of trials in 
phase II of the experiment (first vs. second half). The dependent variable was the time taken for each subject to decide if the two words of every pair rhymed or not.

2.1.3. Stimulus materials. A total of one hundred and forty four pairs of high-frequency words were selected and were then divided into three lists. (All words had Kucera \& Francis [9] frequencies of above 100.) The first list was given to half of the subjects (group A) in phase I of the experiment and contained forty-eight pairs of words, half of which rhymed and had similar spellings, and half did not rhyme and had different spellings. This composition was expected to bias subjects towards using spelling information when making the rhyme judgement. The second list, which was given to the other half of the subjects (group B) in phase I, contained forty eight pairs of words, half of which rhymed but had dissimilar spellings, and half did not rhyme but had similar spellings. The composition of this list was expected to bias subjects away from using spelling information to decide if two words rhymed or not. The third list was given to all subjects in phase II of the experiment and contained a total of forty eight pairs of words. These included twelve pairs that rhymed and had similar spellings, twelve pairs that rhymed but had dissimilar spellings, twelve pairs that did not rhyme but had similar spellings, and finally twelve pairs of words that did not rhyme and had dissimilar spellings. Half of each set of twelve pairs were presented as Block 1 and half as Block 2 . Examples of the stimuli used in each condition of the experiment are shown in Table 1.

2.1.4. Procedure. All the words were recorded and the silence before and after each word was excluded. Four set-ups were constructed: (i) Phase I for group A; (ii) Phase I for group B; (iii) Block 1 of phase II; and (iv) Block 2 of phase II. All subjects received Blocks 1 and 2 in phase II of the experiment.

Each subject was tested individually on the rhyme judgement task. They were given headphones to wear in order to listen to the stimuli and were instructed to press the 'yes' button if the two words of a pair rhymed or the 'no' button if the two words did not rhyme. There was an inter-stimulus interval of $250 \mathrm{msec}$ between the presentation of the two words of each pair. There was also an inter-trial interval of 1 second from the subject's response to the next presentation of a pair of words. Before the analysis of the results, the duration of the second word was added to subjects' reaction times to that word, as the program recorded responses from the offset of the second word of each pair.

In phase I of the experiment subjects were divided randomly into two groups. It must be stressed that the subjects were not given explicit instructions to use or not to use spelling as a strategy; rather, it was hoped that the composition of the stimulus materials would orientate the subjects in group A towards using spelling to assist rhyme decisions as in all forty eight trials rhyme and spelling similarity were congruent, and that subjects in group B would be orientated away from using spelling to the rhyme decision task, as they were given the second list of forty eight stimuli which contained rhyming words with dissimilar spelling and non-rhyming words with similar spelling. In phase II of the experiment, the subjects were given the list, which was common for both groups, that contained another forty eight stimuli but this time with both similarly and dissimilarly spelled rhyming and non-rhyming word pairs. The stimuli in phase II were presented in two halves (or two blocks) of twenty-four trials. (A very short interval occurred between presentation of the two blocks.) This procedure was adopted in order to detect whether any bias effect observed would affect people only for some time and for how long would it last if this was true.

\subsection{Results}

Harmonic mean correct reaction times from the onset of the target word were calculated for each subject and for each stimulus pair. The reaction times of two subjects who made more than $15 \%$ errors were excluded and so the analysis was conducted upon the data from 32 subjects. Responses whose reaction times were either very short (below $500 \mathrm{msec}$ ) or very long (above 3000 $\mathrm{msec}$ ) were excluded from the analysis.

Phase I. The data from phase I, or the biasing stage, of the experiment are shown in Table 2 (analysed by subjects only). For responses to rhymes, there was no difference between group A (who received only similarly spelled rhymes) and group B (who received only dissimilarly spelled rhymes); that is, there was no orthographic facilitation effect [unrelated $\mathrm{t}(30)=0.66$ ]. For responses to non-rhymes, group B (who received only similarly spelled non-rhymes) tended to be slightly slower than group A (who received only dissimilarly spelled non-rhymes), but this orthographic inhibition effect did not reach significance [unrelated $\mathrm{t}(30)=1.19$ ]. However, both of these comparisons were between-subject contrasts.

Phase II. The critical data concern phase II of the experiment, as these enable us to assess the extent (if any) of the bias intended to be established by phase I. All subjects in phase II received the same stimuli. Analyses of variance were performed separately for the rhyme and the non-rhyme pairs in phase II (in order to examine possible effects of bias on the orthographic facilitation and inhibition effects separately), and these analyses contained the following variables: group (A vs. B), Block (1 vs. 


\section{Table 1. Examples of the stimuli used in each condition in phase I and phase II of Experiment 1.}

Phase I, Group A (48 pairs):

24 Rhymes, all with similar spellings: round-sound, blind-mind.

24 Non-rhymes, all with dissimilar spellings: juice-price, bet-bath.

Phase I, Group B (48 pairs):

24 Rhymes, all with dissimilar spellings: birth-earth, heard-third.

24 Non-rhymes, all with similar spellings: gave-have, war-car.

Phase II, Common List, Block 1 (24 pairs):

6 Rhymes with similar spellings: dog-frog, sky-try.

6 Rhymes with dissimilar spellings: could-good, send-friend.

6 Non-rhymes with similar spellings: move-love, blood-food.

6 Non-rhymes with dissimilar spellings: beach-much, club-job.

Phase II, Common List, Block 2 (24 pairs):

6 Rhymes with similar spellings: toy-joy, hate-date.

6 Rhymes with dissimilar spellings: eye-try, wine-sign.

6 Non-rhymes with similar spellings: done-gone, plant-want.

6 Non-rhymes with dissimilar spellings: chance-should, bar-hair.

\section{Table 2. Mean correct reaction times (in $\mathrm{msec}$ ) to make auditory rhyme decisions in phase I of} Experiment 1.

\begin{tabular}{llrll} 
& Rhymes & \multicolumn{2}{l}{ Non-rhymes } \\
Group A: Bias towards spelling & Similar & 996 & Dissimilar & 983 \\
Group B: Bias away from spelling & Dissimilar 935 & Similar & 1020
\end{tabular}

2), and spelling (similar vs. dissimilar). In the ANOVA by subjects, group was manipulated between subjects and the other two variables were manipulated within subjects. In the ANOVA by items, group was a within item variable and the other two were between item variables.

Table 3 shows the results of responses to rhymes in phase II of the experiment. The main effect of spelling was highly significant in the analysis by subjects $[\mathrm{Fs}(1,30)=27.91, \mathrm{MSe}=6618.883, \mathrm{p}<$ $0.0001]$, but not in the analysis by items $[\mathrm{Fi}<1]$. Reaction times to words with similar spelling were faster $(890 \mathrm{msec})$ than to words with dissimilar spelling (966 msec), an overall orthographic facilitation effect of $76 \mathrm{msec}$. The main effect of block was not significant $[\mathrm{Fs}<1 ; \mathrm{Fi}<1]$ and the main effect of group was also non-significant $[\mathrm{Fs}=$ 1.75; $\mathrm{Fi}<1]$, although group A responded slower (959 msec) than group B (897 msec), which may be understandable if one considers that the first group was not previously presented any similarly spelled non-rhyming words, which tended to be responded to slower, whereas group B had experienced such pairs in phase I. There were no significant interactions; in particular, the interaction between group and spelling was absent $[\mathrm{Fs}<1 ; \mathrm{Fi}<1]$. This shows that the orthographic facilitation effect was not significantly different for those subjects biased towards the use of spelling to assist rhyme decisions in group A (89 msec) and those biased away from the use of spelling in group B (63 msec).

Table 4 shows the results of responses to nonrhymes in phase II of the experiment. The main effect of spelling was significant in the analysis by subjects $[\mathrm{Fs}(1,30)=5.50, \mathrm{MSe}=6959.935, \mathrm{p}<$ $0.05]$, but not in the analysis by items [Fi $<1]$. Reaction times to words with similar spelling were slower $(982 \mathrm{msec})$ than to words with dissimilar spelling (947 msec), an overall orthographic inhibition effect of $35 \mathrm{msec}$. The main effect of block was very close to significance in the analysis by subjects $[\mathrm{Fs}(1,30)=3.96, \mathrm{MSe}=6921.641, \mathrm{p}=$ $0.056]$, but not in the analysis by items $[\mathrm{Fi}<1]$. Reaction times to block 1 were faster $(950 \mathrm{msec})$ than to block 2 (979 $\mathrm{msec})$. The main effect of group was significant in the analysis by items $[\mathrm{Fi}(1,20)=17.64, \mathrm{MSe}=2448.425, \mathrm{p}<0.001]$, but not in the analysis by subjects $[\mathrm{Fs}(1,30)=2.12$, MSe $=93065.324, \mathrm{p}=0.16]$. Subjects in group A were slower $(1004 \mathrm{msec})$ than subjects in group B (925 $\mathrm{msec}$ ). There were no significant interactions. In particular, the interaction between group and spelling was absent $[\mathrm{Fs}<1 ; \mathrm{Fi}<1]$, which shows that the orthographic inhibition effect was not significantly different for those subjects biased towards the use of spelling to assist rhyme decisions in group A (32 $\mathrm{msec}$ ) and those biased away from the use of spelling in group B (37 msec). 
Table 3. Mean correct reaction times (in msec) to rhymes of phase Il of the auditory rhyme decision task in Experiment 1. (orthographic facilitation effects are also shown.)

$\begin{array}{lccc}\text { BLOCK 1 } & & & \\ \text { Group A } & \text { Similar } & \text { Dissimilar } & \text { Facilitation } \\ \text { By subjects } & 932 & 1008 & 76 \\ \text { By items } & 926 & 1008 & 82 \\ \text { Error rates } & 7.3 \% & 10.4 \% & \\ \text { Group B } & & & \\ \text { By subjects } & 866 & 926 & 60 \\ \text { By items } & 881 & 922 & 41 \\ \text { Error rates } & 8.3 \% & 2.1 \% & \\ \text { BLOCK 2 } & & & \\ & \text { Similar } & \text { Dissimilar } & \text { Facilitation } \\ \text { Group A } & & & \\ \text { By subjects } & 897 & 999 & 102 \\ \text { By items } & 900 & 984 & 84 \\ \text { Error rates } & 9.4 \% & 5.2 \% & \\ \text { Group B } & & & \\ \text { By subjects } & 864 & 930 & 66 \\ \text { By items } & 968 & 976 & 8 \\ \text { Error rates } & 11.5 \% & 6.3 \% & \end{array}$

Table 4. Mean correct reaction times (in msec) to non-rhymes of phase II of the auditory rhyme decision task in Experiment 1. (orthographic inhibition effects are also shown)

$\begin{array}{llll}\begin{array}{l}\text { BLOCK 1 } \\ \quad \text { Similar }\end{array} & \text { Dissimilar } & \text { Inhibition } & \\ \text { Group A } & & & \\ \text { By subjects } & 1022 & 980 & 42 \\ \text { By items } & 990 & 971 & 19 \\ \text { Error rates } & 1.0 \% & 3.1 \% & \\ \text { Group B } & & & \\ \text { By subjects } & 913 & 884 & 29 \\ \text { By items } & 898 & 898 & 0 \\ \text { Error rates } & 4.2 \% & 6.3 \% & \\ \text { BLOCK 2 } & & & \\ & \text { Similar } & \text { Dissimilar } & \text { Inhibition } \\ \text { Group A } & & & \\ \text { By subjects } & 1017 & 996 & 21 \\ \text { By items } & 999 & 969 & 30 \\ \text { Error rates } & 2.1 \% & 1.0 \% & \\ \text { Group B } & & & \\ \text { By subjects } & 976 & 929 & 47 \\ \text { By items } & 974 & 919 & 55 \\ \text { Error rates } & 3.1 \% & 2.1 \% & \end{array}$

\subsection{Discussion}

The aim of Experiment 1 was to determine whether, for adult subjects, the orthographic effects in the rhyme decision task are automatic or whether subjects activate and use spelling deliberately in some consciously mediated process. The experiment tested the hypothesis that the composition of the stimuli presented in phase I of the experiment would

bias subjects either towards or away from using spelling information in making rhyme decisions. The results from Experiment 1 show very clearly that the orthographic facilitation effect for responses to rhymes and the orthographic inhibition effect for responses to non-rhymes were not reliably different for subjects biased towards the use of spelling to assist rhyme decisions (in group A) and those biased away from the use of spelling (in group B). (In the 
present experiment, the orthographic facilitation effects were larger, and consistently more reliable, than the orthographic inhibition effects, but similar results were found for both effects.) Furthermore, this was true for both blocks of trials in phase II of the experiment, showing that there were no temporary or transient effects of bias, which might have been detected only for the early trials of phase II. The subjects in both groups A and B appeared to have activated and used spelling in their auditory rhyme decision performance.

There exist two possible explanations of the fact that the subjects tested in Experiment 1 did not show any orthographic bias effects in phase II as it was intended by the design of phase I. The first is that the manipulation of bias used by the experiment was insufficiently strong or effective. It may be argued that the number of the stimulus word pairs used in phase I (which was forty eight) was not enough to bias people and that the experience of more trials would be required. However, it was expected that hearing 24 rhyming pairs that have either the same or, especially, different spelling patterns should have produced some effect of bias, if such effects could be demonstrated at all. Although the subjects in group B produced faster response times overall than those in group A in phase II of the experiment, this cannot be taken as evidence for differences in strategy, particularly as group did not interact with the orthographic effects. It is possible that the difference in overall response times could simply reflect between subject variability. (Subjects in the two groups were not matched initially for their overall reaction time, but they were randomly allocated to each group.) It is also possible that group B was faster because they had heard non-rhyming pairs that were similarly spelled in both phase I and phase II of the experiment.

The second explanation, and the one which is favoured here, is that the activation of orthographic knowledge in the auditory rhyme decision task is automatic and does not represent a strategic behavior that people adopt specifically to aid performance in the task. In other words, the suggestion is that people cannot be biased, as they activate the spellings of the words they hear, even though they are not asked to do so, totally automatically. The orthographic inhibition effects --which reflect the 'cost' of such automatic activation and influence of spelling information-- were smaller than the orthographic facilitation effects (which could be seen as the 'benefit' of the use of spelling) in Experiment 1. However, they were consistently present, although not always significant. If the activation of the spelling of a heard word is an automatic process, then it is reasonable to assume that it could not be selectively applied, which would lead to inhibition as well as facilitation effects. The important feature of the results is that the orthographic facilitation effects (which were large and statistically significant) were the same for both groups A and B. This implies that, in the purely phonological task of rhyme decision, people access automatically the representations of the words they hear; it is as though they 'see' the words when they hear them.

\section{Experiment 2: Set effects in children}

Experiment 2 used exactly the same design and the same stimuli as Experiment 1 but, instead of using adults as subjects, children of 9 and 11 years of age participated. It has been found [10] that children show the same orthographic effects as adults, as long as they know the spellings of the words used: they are faster to say that two spoken words rhyme when these are spelled similarly than when they are spelled dissimilarly, and they are slower to say that two words do not rhyme if they have similar rather than dissimilar spellings. These orthographic facilitation and inhibition effects can only be due to the activation of the spelling of the words used in the rhyme decision task.

Experiment 2 examined whether these effects of orthography can be attributed to the automatic activation of spelling, or to the strategic access and use of spelling information by children. Experiment 1 showed that adults were not biased either towards or away from using spelling in the rhyme judgement task by the composition of trials in phase I of the task. There were essentially identical orthographic facilitation and inhibition effects observed for subjects who were biased away from using spelling as those biased towards using spelling to assist performance in the rhyme decision task, which suggests that the activation of spelling was automatic. The present experiment was designed to see if these effects could also be said to be automatic in children who, in contrast to adults, might be expected to be less 'fluent' spellers. It is possible that bias effects would be greater in children than in adults.

In each age group, half of the children were biased towards reliance on spelling to assist rhyme decisions in phase I, and half were biased away from such reliance. After this biasing in phase I of the experiment, all children received the same two blocks of stimuli in phase II, which contained pairs of words from all the four categories in order to test the effects of any orthographic bias.

\subsection{Method}

3.1.1. Participants. Fifty-seven children from a Roman Catholic, English language primary school in Cardiff participated in the experiment. There were twenty-eight 9-year-olds (sixteen male and twelve female) and twenty-nine 11-year-olds (fourteen male and fifteen female). All were 'normal' readers and 
spellers for their age (as determined by the school's own assessments).

3.1.2. Design. The independent variables manipulated in the experiment were: (i) the between subjects variable of age (9- vs. 11-year-olds); (ii) the between subjects variable of group (where group A was biased towards using spelling and group B was biased away from using spelling in phase I); (iii) rhyme (rhyme vs. non-rhyme); (iv) spelling (similar vs. dissimilar); and (v) half of trials in phase II of the experiment. The dependent variable was the time taken for each subject to decide if the two words of every pair rhymed or not.

3.1.3. Stimulus materials. The same one hundred and forty four pairs of words as used in Experiment 1 were used. Again the composition of the experiment was designed so that in phase I of the experiment half of the subjects (group A) would be biased towards using spelling information when making the rhyme judgement, by receiving pairs that rhymed and had similar spellings as well, and the other half (group B) would be biased away from using spelling information, by receiving pairs that rhymed but had dissimilar spellings. In phase II, which was common to both groups of subjects, the forty eight pairs were rhyming with similar spellings, rhyming with dissimilar spellings, non-rhyming with similar spellings, and finally non-rhyming with dissimilar spellings. Half of those pairs were presented as Block 1 (which contained pairs from all four categories) and half as Block 2 (which again contained pairs from all four conditions).

3.1.4. Procedure. All the words were recorded and edited as before. The stimuli were presented randomly and subjects' responses were timed from the second word of every pair presented. Again four set-ups were constructed: (i) Phase I for group A; (ii) Phase I for group B; (iii) Block 1 of phase II; and (iv) Block 2 of phase II. All subjects received Blocks 1 and 2 in phase II of the experiment.

Each subject was tested individually on the rhyme judgment task. They were given headphones to wear and were instructed to press the 'yes' button if the two words of a pair rhymed or the 'no' button if the two words did not rhyme. A short practice trial was given before the experiment started in order to be sure that subjects understood what they were asked to do. The procedure was exactly the same as in the previous experiment with the same intervals between the presentation of the two words of each pair and from the subject's response to the next presentation of a pair of words. Before any analysis had taken place, the durations of the second words were added as before to subjects' reaction times.
In phase I of the experiment subjects of each age were randomly allocated to two groups. Group A was orientated, as described above, towards using spelling to make rhyme decisions, as those subjects have received in phase I of the experiment the list of forty eight stimuli that contained rhyming words with same spelling and non-rhyming words with different spelling. Group B was orientated away from using spelling to the rhyme decision task, as those subjects have received in phase $I$ of the experiment the list of forty-eight stimuli that contained rhyming words with dissimilar spelling and non-rhyming words with similar spelling. After phase I, there was a brief interval before phase II was presented, which was common for both groups (and contained forty eight trials with both rhyming and non-rhyming words with both similar and dissimilar spelling). These stimuli were presented in two blocks of twenty-four trials each with a very short interval between them. The entire experiment took approximately ten minutes for each child.

\subsection{Results}

Harmonic mean correct reaction times from the onset of the target word were calculated for each subject and for each stimulus pair. The reaction times of seventeen subjects (eight 9-year-olds and nine 11year-olds) who made more than six errors in the rhyme decision task were excluded from the analysis. So the analysis was conducted upon 40 subjects' reaction times (twenty 9-year-olds and twenty 11-year-olds). Also very short reaction times (below $500 \mathrm{msec}$ ) and very long ones (above 3000 $\mathrm{msec}$ ) were excluded from the analysis

Phase I. The analysis on the data from phase I of the experiment, where children were being primed towards or away from using spelling knowledge in the rhyme task, revealed the following results (see Table 5):

Two two-way analyses of variance were performed (by subjects only), one for rhymes and one for non-rhymes. Each analysis contained the two between-subject factors of spelling (similar vs. dissimilar) and age (9- vs. 11-year-olds). In the analysis of the rhymes, no effects reached significance $(F<1.2)$, although there was a trend for responses to be faster to similarly spelled than to dissimilarly spelled pairs (1217 vs. $1274 \mathrm{msec}$ ) In the analysis of the non-rhymes, spelling was significant $[\mathrm{F}(1,36)=11.23, \mathrm{MSe}=34079.606, \mathrm{p}<$ 0.005]. Responses to words with similar spellings were slower (1412 msec) than to words with dissimilar spelling (1217 msec), a clear orthographic inhibition effect. Both the main effect of age and the interaction between age and spelling failed to reach significance $(\mathrm{F}<1)$. 
Table 5. Mean correct reaction times (in msec) to make auditory rhyme decisions in phase I of Experiment 2.

9-year-olds

Rhymes Non-rhymes

Group A: Bias towards spelling Similar $1205 \quad$ Dissimilar 1185

Group B: Bias away from spelling Dissimilar 1248 Similar 1399

11-year-olds

Group A: Bias towards spelling Similar $1230 \quad$ Dissimilar 1248

Group B: Bias away from spelling Dissimilar 1300 Similar 1425

Table 6. Mean correct reaction times (in $\mathrm{msec}$ ) to rhymes in phase II of the auditory rhyme decision task in Experiment 2, for each age group and for each block of trials. (Facil. $=$ the magnitude of the orthographic facilitation effect.)

9-Year-olds

BLOCK 1 Group A

By subjects 1198

Similar Dissimilar Facil.

By items

$\%$ errors

Group B

By subjects 1323

By items

$\%$ errors

$1341 \quad 143$

$1198 \quad 1325$

$3.3 \% \quad 8.3 \%$

$1273 \quad-50$

$1280 \quad 1179$

BLOCK 2 Group A

$16.6 \% \quad 15 \%$

By subjects 1081

By items

$1248 \quad 167$

Group B

$\begin{array}{ll}1079 & 1216 \\ 8.3 \% & 13.3 \%\end{array}$

By subjects 1287

By items

$1256-31$

$\%$ errors

1203

1210

$8.3 \%$

$11.6 \%$

11-Year-olds

Similar Dissimilar Facil.

BLOCK 1 Group A

By subjects 1278

By items

$\%$ errors Group B

By subjects 1231
By items

By subjects 1231
By items

$\%$ errors

$1317 \quad 39$

1268

1247

$6.6 \%$

$6.6 \%$

$1259 \quad 28$

$1182 \quad 1205$

$8.3 \% \quad 10 \%$

BLOCK 2 Group A

By subjects 1271

$1356 \quad 85$

By items

1256

$\%$ errors

1256

1301

45

Group B

By subjects 1104

By items

$\%$ errors

1083

1224

$5 \%$

$10 \%$

120

1149

66

$5 \%$ 
Phase II. The critical data of phase II of the experiment were analysed to assess the extent (if any) of the bias intended to be established by phase I. All children in phase II received exactly the same stimuli.

In order to examine orthographic facilitation and inhibition effects, analyses of variance were performed separately for responses to rhymes and non-rhymes. These analyses contained the following variables: age (9- vs. 11-year-olds), group (A vs. B), and spelling (similar vs. dissimilar). In the ANOVA by subjects, age and group were manipulated between subjects and spelling was manipulated within subjects. In the ANOVA by items, age and group were within item variables and spelling was a between item variable.

Table 6 shows the data for responses to rhymes. The main effect of spelling was significant by subjects $[\mathrm{Fs}(1,36)=4.90, \mathrm{MSe}=32081.797, \mathrm{p}<$ $0.05]$, but not by items [Fi $<1]$. Responses to words with similar spellings were faster $(1222 \mathrm{msec})$ than to those with dissimilar spellings (1284 msec), an overall orthographic facilitation effect of $62 \mathrm{msec}$. The main effect of block was almost significant by subjects $[\mathrm{Fs}(1,36)=3.89, \mathrm{MSe}=24882.299, \mathrm{p}=$ $0.056]$, but not by items $[\operatorname{Fi}(1,20)=1.58]$. Subjects were generally slower in the first block than in the second block of phase II of the experiment (1278 vs. $1228 \mathrm{msec}$ ), which may reflect a practice effect on overall reaction times. The main effect of group was significant in the analysis by items $[\mathrm{Fi}(1,20)=6.940$, $\mathrm{MSe}=8537.715, \mathrm{p}<0.025]$, but not in the analysis by subjects $[\mathrm{Fs}<1]$; group A tended to be slower (1236 msec) than group B (1186 msec). The important interaction between group and spelling did not reach significance in the analysis by subjects $[\mathrm{Fs}(1,36)=2.61, \mathrm{p}=0.11]$, but was close to significance in the analysis by items $[\operatorname{Fi}(1,20)=3.78$, $\mathrm{MSe}=8537.715, \mathrm{p}=0.067] . \quad$ The orthographic facilitation effect was larger in group A, who were biased towards spelling (108 msec by subjects and $72 \mathrm{msec}$ by items), than in group B, who were biased away from spelling (17 msec by subjects and $-1 \mathrm{msec}$ by items). Analyses of simple main effects showed that the orthographic facilitation effect was significant for group $\mathrm{A}$ in the analysis by subjects $[\mathrm{Fs}(1,36)=7.33, \mathrm{MSe}=32081.797, \mathrm{p}<0.025]$, but not quite in the analysis by items $[\operatorname{Fi}(1,40)=2.85$, MSe $=21961.581, \mathrm{p}=0.099]$, and was not significant for group B [Fs $<1 ; \mathrm{Fi}<1]$. The threeway interaction between group, spelling and age approached significance in the analysis by subjects $[\mathrm{Fs}(1,36)=3.35, \mathrm{MSe}=32081.797, \mathrm{p}=0.076]$ and was significant in the analysis by items $[\operatorname{Fi}(1,20)=$ $8.18, \mathrm{MSe}=8206.865, \mathrm{p}<0.01]$. This showed that the difference between the two biasing conditions (i.e., group A vs. group B) was only true for the 9year-olds (where the orthographic facilitation effect was $155 \mathrm{msec}$ for group A and $-41 \mathrm{msec}$ for group
B); for the 11-year-olds, the orthographic facilitation effects were essentially equal for group A (62 msec) and group B (74 msec).

The interaction between age and group was not significant by subjects $[\mathrm{Fs}(1,36)=1.67]$ but was significant by items $[\mathrm{Fi}(1,20)=11.63$, MSe $=$ 8206.865, $\mathrm{p}<0.005]$. The 9 -year-olds in group A (who were biased towards using spelling) were faster than those in group B (who were biased away from using spelling), whereas the 11-year-olds showed the opposite pattern of results. The interaction between block, age and group was significant by items $[\mathrm{Fi}(1,20)=6.592, \mathrm{MSe}=8206.865, \mathrm{p}<0.025]$, but not quite by subjects $[\operatorname{Fs}(1,36)=3.06$, MSe $=$ 24882.299, $\mathrm{p}=0.089]$. The four-way interaction between age, group, spelling and block was not significant [Fs $<1 ; \mathrm{Fi}<1]$.

Table 7 shows the data for responses to nonrhymes. The main effect of spelling did not reach significance $[\mathrm{Fs}(1,36)=1.67 ; \mathrm{Fi}<1]$. Overall, the orthographic inhibition effect was only $39 \mathrm{msec}$. The important interaction between group and spelling was not significant [Fs $<1 ; \quad \mathrm{Fi}=1.14]$, although the trend was for the orthographic effect to be smaller in group A who were biased towards spelling ( $13 \mathrm{msec}$ by subjects and $-6 \mathrm{msec}$ by items), than in group B who were biased away from spelling (65 msec by subjects and $41 \mathrm{msec}$ by items), although none of these effects reached significance in analyses of simple main effects. The 3-way interaction between group, spelling and age (which was almost significant in the analysis of the rhyme data) was completely absent in the non-rhyme data [Fs $<0.1 ; \mathrm{Fi}<1]$.

The interaction between age and group did not reach significance by subjects $[\mathrm{Fs}(1,36)=2.22$, MSe $=229842.867, \mathrm{p}=0.15]$, but was significant by items $[\mathrm{Fi}(1,20)=10.57, \mathrm{MSe}=9998.944, \mathrm{p}<0.005]$. The 9-year-olds in group A (who were biased towards using spelling) were faster than those in group B (who were biased away from using spelling), whereas the 11-year-olds showed the opposite pattern of results. Furthermore, the fourway interaction between age, group, spelling and block was also significant by items $[\mathrm{Fi}(1,20)=4.68$, MSe $=9998.944, \mathrm{p}<0.05]$, but not by subjects $[\mathrm{Fs}(1,36)=1.80, \mathrm{MSe}=34760.153, \mathrm{p}=0.19]$.

The analysis on the errors made on the rhymes did not show any significant result, whereas the analysis on the errors made on the non-rhymes showed that the effect of block (first versus second) was significant $[\mathrm{F}(1,36)=6.24, \mathrm{MSe}=0.290, \mathrm{p}<0.025]$. No other effects were significant for the error data; error rates were generally rather low and theoretically unrevealing in this experiment. 
Table 7. Mean correct reaction times (in msec) to non-rhymes in phase II of the auditory rhyme decision task in Experiment 2, for each age group and for each block of trials. (Inhib. $=$ the magnitude of the orthographic inhibition effect.)

9-Year-olds

BLOCK 1 Group A

Similar Dissimilar Inhib.

By subjects 1297

By items $\quad 1290 \quad 1291$

$\%$ errors $\quad 1.6 \% \quad 3.3 \%$

Group B

By subjects $1546 \quad 1453 \quad 93$

$\begin{array}{llll}\text { By items } & 1411 & 1320 & 91 \\ \% \text { errors } & 16.6 \% & 6.6 \% & \end{array}$

BLOCK 2 Group A

By subjects $\quad 1349 \quad 1259 \quad 90$

By items $\quad 1321 \quad 1309$

\% errors $\quad 6.6 \% \quad 3.3 \%$

Group B

By subjects $1458 \quad 1395 \quad 63$

$\begin{array}{llll}\text { By items } & 1329 & 1326 & 3\end{array}$

11-Year-olds

$\%$ errors $\quad 11.6 \% \quad 15 \%$

BLOCK 1 Group A

$\begin{array}{crrr}\text { By subjects } 1361 & 1296 & 65 \\ \text { By items } & 1315 & 1308\end{array}$

$\begin{array}{llll}\text { By items } & 1315 & 1308 & 7\end{array}$

Group B

By subjects $\quad 1328 \quad 1291 \quad 37$

$\begin{array}{llll}\text { By items } & 1237 & 1280 & -43\end{array}$

BLOCK 2 Group A

By subjects $1356 \quad 1450 \quad-94$

$\begin{array}{llll}\text { By items } & 1312 & 1410 & -98\end{array}$

Group B

$\begin{array}{llll}\text { By subjects } & 1322 \quad 1257 \quad 65\end{array}$

$\begin{array}{llll}\text { By items } & 1289 & 1182 & 107 \\ \% \text { errors } & 8.3 \% & 6.6 \% & \end{array}$

Table 8. The orthographic effects (in msec) found in Experiment 1 (with adults) and Experiment 2 (with children), calculated from the analyses by subjects.

Facilitation Inhibition

Adults

$\begin{array}{ccc}\text { Group A } & 89 & 32 \\ \text { Group B } & 63 & 38 \\ \text { Year-olds } & & \\ \text { Group A } & 155 & 41 \\ \text { Group B } & -41 & 78 \\ \text {-Year-olds } & & \\ \text { Group A } & 62 & -15 \\ \text { Group B } & 74 & 51\end{array}$




\subsection{Discussion}

Experiment 2 examined whether the orthographic effects shown by 9- and 11-year-old children in phase II of a rhyme decision task could be biased by the composition of the stimulus word pairs (that manipulated the congruence between spelling similarity and rhyme) presented in phase I of the experiment. If they were not, it was reasoned that any orthographic effects shown would reflect the automatic activation and use of spelling in the auditory rhyme decision task.

For responses to rhymes, a fairly clear pattern of results emerged (although some of the effects did not always reach significance). For the 9-year-old children, there was a reliable and fairly substantial orthographic facilitation effect (of $155 \mathrm{msec}$ ) for those (in group A) who were biased towards the use of spelling; however, for those (in group B) who were biased away from spelling, there was no reliable facilitation effect $(-41 \mathrm{msec})$. This showed that the manipulation in phase I of the experiment was indeed effective, indicating that, for these younger children, the effects of spelling information in the auditory rhyme decision task reflected some strategic reliance on spelling information to aid rhyme decisions. It would appear that, for the 9-yearold children, the orthographic facilitation effect was not solely the result of the automatic activation and use of the spellings of the words. It would seem that only those children who were 'encouraged' to use spelling to assist their rhyme decisions by the composition of the trials in phase I, actually used the similarity of the two words' spellings to facilitate their positive responses to rhymes in phase II of the experiment. For the 11-year-old children, the orthographic facilitation effects found in phase II were essentially the same for both group A $(62 \mathrm{msec})$ and group B (74 msec). The older children therefore showed a similar pattern of results as the adults tested in Experiment 1, namely, no effect of bias, which suggests that the activation and use of spelling reflected an automatic process.

The data for responses to non-rhymes were less clear-cut (and indeed, as was also found in Experiment 1 with adults, the orthographic inhibition effects were generally smaller and less reliable than the orthographic facilitation effects). For the 9-yearolds, there was an orthographic inhibition effect of $41 \mathrm{msec}$ for those in group A and an effect of 78 msec for those in group B. For the 11-year-olds, there was no effect for those in group A $(-15 \mathrm{msec})$ and a small effect of $51 \mathrm{msec}$ for those in group B. It would appear that any strategic effect due to any reliance on spelling similarity had a greater effect on positive responses to rhymes than on negative responses to non-rhymes, where the orthographic inhibition effects were found to be smaller and less reliable.
The basic question asked by this experiment was whether the orthographic effects shown by children in the auditory rhyme decision task could be said to be due either to automatic or to strategic activation of the spellings of the words the children hear. It would appear that the orthographic effects shown by children aged 9-years-old were due to the strategic activation and use of spelling information; the younger children who were biased towards using spelling information in phase I of the experiment showed a clear orthographic facilitation effect, whereas those biased away from spelling showed no reliable effect. For these children, it would seem that they actively generated and used the spellings of the words to assist their rhyme decisions when such a task-specific strategy was strongly encouraged by the composition of the trials in phase $\mathrm{I}$ of the experiment. Spelling similarity and rhyme were perfectly congruent in phase I for group A and the twenty children in this group appeared to use spelling to assist their rhyme decisions, although the evidence for the 'negative' use of spelling similarity to assist making a non-rhyme response was less clear. In contrast, the 11-year-old children showed no effects of bias from the composition of the trials in phase $I$ of the experiment and so their orthographic effects appeared to reflect the automatic activation and use of spelling information.

There are two possible reasons for the difference in pattern of results for the two groups of children. First, it is possible that, by the age of 11-years, children become more skilled in their use of spelling and so, like adults, automatically activate and use the spellings of words to assist performance, which therefore leads to an absence of any effect of bias. An alternative explanation, however, is that the younger children also activate spelling automatically from heard words but this orthographic information does not so readily influence performance in the rhyme decision task. If the younger children were actually less confident in making rhyme decisions, then they may have only relied upon any additional information provided to them within the experiment when this was strongly 'encouraged' (i.e., when in group A). Such an account would also explain why the effects of bias shown by group A of the 9-yearolds also lasted to the second block of trials in phase II of the experiment. However, there were no reliable differences between the two age groups in either overall reaction time or accuracy, and as it has been found (Lipourli \& Barry) 9-year-old children show orthographic effects when not biased in any way for those words they are able to spell. Given the inconsistency between those results, the tentative conclusion is that 9-year-old children are less efficient in the use of spelling information in the auditory rhyme decision task. It is not possible to conclude confidently that these children do not have any automatic activation of a spoken word's spelling. 


\section{General discussion}

This paper has reported two experiments, one with adults and one with 9- and 11-year-old children. Both experiments were based upon the assumption that if the orthographic effects observed in the auditory rhyme decision task reflected the automatic activation and influence of the spellings of the words, then they would be unaffected by the composition of the stimulus materials presented in phase I of the experiment. However, if the orthographic effects reflected the operation of a taskspecific strategy in which participants actively and deliberately used spelling to assist their rhyme decision performance in the task, then they should be biased by the 'set' established by the composition of the trials in phase I; this logic would expect that the orthographic effects should be seen only by those subjects who were biased towards the use of spelling (or, at least, they should be greater for subjects in group A than in group B).

The orthographic effects observed in phase II of the two experiments (by summing over the two blocks of trials) are summarized in Table 8 .

It is clear that both groups of adult subjects tested in Experiment 1 showed essentially equal orthographic effects in the auditory rhyme decision task. From the logic presented, it was concluded that these effects reflect the automatic use of spelling in this task, as there were no effects of bias either towards or away from the use of spelling similarity as generated by the composition of trials in phase I of the experiment. Although it is possible that the absence of any effect of bias established by the 'set' of the trials in phase I of the experiment could have been due to the manipulation of bias used being insufficiently strong or effective, it was argued that this is unlikely to have been the complete explanation. (For one thing, the manipulation was effective for the 9-year-old children.) Instead, it was argued that the activation of the spellings of spoken words in the auditory rhyme decision task is automatic and so reflects implicit effects of spelling. As was claimed in the discussion of Experiment 1, it is as though the subjects 'see' the words when they hear them and so the similarity of the spellings of the two words assists positive responses to rhymes and interferes with negative responses to non-rhymes.

The 11-year-old children tested in Experiment 2 also showed no effects of bias, which can also be taken as evidence for the automatic use of spelling information. However, the 9-year-old children did show a bias (or 'set') effect; only those in group A, who were biased towards the use of spelling similarity in phase I, showed a reliable orthographic facilitation effect in phase II of the experiment. This result may be taken to indicate that these younger children used spelling information to assist their rhyme decisions only when the circumstances of the experiment encouraged reliance upon spelling similarity. However, given that it has been found (Lipourli \& Barry) that 9-year-old children show reliable orthographic effects for the words whose correct spellings they know (when there are no biasing effects), it is not possible to conclude that they did not activate spelling information. Rather, it may be the case that they strategically abandoned the activation of spelling when the biasing conditions introduced in phase I of the experiment discouraged reliance upon spelling similarity to inform rhyme decisions.

\section{References}

[1] Seidenberg, M.S., and Tanenhaus, M.K. (1979). Orthographic effects on rhyme monitoring. Journal of Experimental Psychology: Human Learning and Memory, $5,546-554$

[2] Bryant, P.E., Bradley, L., MacLean, M., and Crossland, J. (1989). Nursery rhymes, phonological skills and reading. Journal of Child Language, 16, 407-428.

[3] Bryant, P.E., MacLean, M., and Bradley, L. (1990). Rhyme, language, and children's reading. Applied Psycholinguistics, 11, 237-252.

[4] Treiman, R. (1993). Beginning to spell: A study of firstgrade children. New York: Oxford University Press.

[5] Barron, R.W. (1991). Proto-literacy, literacy, and the acquisition of phonological awareness. Learning and Individual Differences, 3, 243-255.

[6] Barron, R.W. (1994). The sound-to-spelling connection: Orthographic activation in auditory word recognition and its implications for the acquisition of phonological awareness and literacy skills. In Berninger, V.W. (Ed.), The varieties of orthographic knowledge, I: Theoretical and developmental issues, 219-242. Kluwer Academic Publishers, Dordrecht, Netherlands.

[7] Goswami, U., and Bryant, P.E. (1990). Phonological skills and learning to read. Lawrence Erlbaum Associates, Hove, England.

[8] Barry, C., and Seymour, P.H.K. (1988). Lexical priming and sound-to-spelling contingency effects in nonword spelling. Quarterly Journal of Experimental Psychology, 40A, 5-40.

[9] Kucera, H., and Francis, W.N. (1967). Computational analysis of present-day American English. Providence, RI: Brown University Press.

[10] Lipourli, E. (2014). Orthographic effects in auditory rhyme decisions in children. Procedia-Social and Behavioural Sciences Journal, 116, 5143-5151. 